\title{
Association between antenatal care visits and adverse pregnancy outcomes: a retrospective cross-sectional study among Ghanaian women
}

\author{
ALHASSAN SIBDOW ABUKARI ( $\sim$ alhassan.sibdow@wiuc-ghana.edu.gh ) \\ Wisconsin International University College Ghana https://orcid.org/0000-0002-7530-6501 \\ Shamsudeen Mohammed \\ Nalerigu University College of Nursing and Allied Health Sciences \\ Ibrahim Yakubu \\ Gushegu Nursing and Midwifery Training College \\ Waliu Jawula Salisu \\ Tehran University of Medical Sciences School of Nursing and Midwifery \\ Yakubu H. Yakubu \\ Auckland University of Technology Akoranga campus
}

Research article

Keywords: Antenatal care, adverse pregnancy, still births, preterm, small-for-gestational-age, low birth weight

Posted Date: March 26th, 2021

DOl: https://doi.org/10.21203/rs.3.rs-332203/v1

License: (c) (1) This work is licensed under a Creative Commons Attribution 4.0 International License. Read Full License 


\section{Abstract}

\section{Background}

The study aimed to determine the association between antenatal visits and adverse pregnancy outcomes among Ghanaian women in the North East Region.

\section{Methods}

We analysed data on the birth records of 2907 women who delivered at Baptist Medical Centre between January 2018 to December 2018. Binary logistic regression was used to assess the association between antenatal visits and four adverse pregnancy outcomes - preterm birth, low birth weight, small-forgestational-age, and stillbirth.

\section{Results}

Our analysis showed that ANC attendance offered some protection against preterm birth, low birth weight, small-for-gestational-age, and stillbirth in the study sample, albeit with variations in the protective effect depending on the number of visits attended. An increase in the number of ANC visits was associated with a decrease in the occurrence of the adverse pregnancy outcomes, except for low birth weight where the protective effect was observed only after four ANC visits. Adolescent mothers attended the least number of ANC visits during the study period. Our analysis suggests that the effect of ANC attendance on preterm birth and low birth weight differed depending on the age of the mother. Among mothers who never attended any ANC visits, adolescent mothers and older mothers had higher odds of low birth weight compared to mothers aged 20-30years. Surprisingly, the odds of preterm birth among the mothers who never attended any ANC visits was lower in adolescent mothers and older mothers compared to mothers aged 20-30years. For mothers who attended four or more ANC visits, the odds of low birth weight were higher in adolescent mothers and lower in older mothers compared to mothers aged 20-30years. However, the odds of preterm birth among the mothers who attended more than four ANC visits was higher in adolescent mothers and older mothers compared to mothers aged 20-30years.

\section{Conclusion}

The findings highlight the importance of ANC in preventing adverse pregnancy outcomes and the need for every pregnant woman to initiate and ensure adequate ANC contacts. The results also highlight the need to prioritise adolescents and older pregnant women for ANC.

\section{Background}

Globally, there has been a commendable progress in maternal-child-health services coverage in the past decade. However, progress in pregnancy outcomes is stagnating especially in low and middle-income countries (1-6). In 2017, nearly 810 women died daily from preventable pregnancy and childbirth related causes with $94 \%$ of the deaths occurring in lower-middle-income countries (7). Furthermore, in 2019 
about 2.4 million children died in the first month of life and $47 \%$ of all under-5 deaths occurred in the newborn period with about one third dying on the day of birth and close to three quarters dying within the first week of life (8). Evidence suggests that effective interventions exist at an affordable cost for the prevention or management of almost all pregnancy and childbirth complications (6). For instance, about $70 \%$ of the global maternal and neonatal disease burden could be reduced through optimal modification and uptake of antenatal care services (7).

The vision of the World Health Organization (WHO) is for every pregnant woman and newborn to receive quality healthcare throughout pregnancy, childbirth and post-delivery (6). This vision can be accomplished through appropriate delivery of skilled antenatal care (ANC) and postnatal care (PNC) services. Antenatal care involves the care delivered by skilled health-care workers to pregnant women to safeguard the best health conditions for both mother and baby during pregnancy and childbirth. ANC services aim to improve the wellbeing of the mother and foetus through risk identification, monitoring of pregnancy, prevention of pregnancy-related ailments, management of concurrent diseases, detection of complications, responding to women's complaints, preparing for birth, and promoting healthy behaviours through health education and health promotion (5-12). Some specific components of the ANC services rendered to pregnant women include administration of Iron-folic acid, nutritional education, vaccination, screening for malaria, pre-eclampsia, bacteriuria and syphilis infections and treatment of same. These interventions are reported to be cost-effective globally (13)(14). The benefits of antenatal care (ANC) to babies include increased intrauterine growth, reduced risk of infection and increased survival $(3,5)$.

A minimum of eight antenatal care contacts is recommended by the WHO to reduce perinatal morbidity and mortality and improve women's experience of care through regular contact with health-care practitioners during pregnancy. This also allows women to receive services vital to their health and that of their unborn children. Reports indicate that women receiving at least 4 or more antenatal care visits differ significantly amongst countries, ranging from $21 \%$ in sub-Saharan Africa to over $90 \%$ in developed countries (15). Nonetheless, most pregnant women access skilled antenatal care at least once, only $60 \%$ receive four or more antenatal care visits $(7,8,15,16)$. The services provided at ANC and the benefits it offers depend on the number of ANC visits. For instance, a study found a $76 \%$ higher risk of low birth weight associated with premature delivery for women who received fewer ANC clinical services compared with women who received more ANC clinical services (17)

This study investigates the influence of ANC on Preterm birth, small-for-gestational-age, low birth weight and stillbirth. Infants with these adverse pregnancy outcomes are reported to have increased risk of perinatal morbidity and mortality than normal foetuses and infants. For instance, complications of preterm birth are the leading cause of newborn deaths worldwide, and now the second leading cause of death in children under 5 , after pneumonia, with more than 1 million deaths each year(18-20). An estimated 20.5 million infants, representing $14.6 \%$ of all births worldwide, were born with low birth weight in 2015 with $91 \%$ of them from low- and middle-income countries(21). Annually, approximately 2.6 million stillbirths occur worldwide with about $98 \%$ of the deaths occurring in low-and middle-income countries and around three-quarters in sub-Saharan Africa and South Asia(22). 
Factors such as maternal age $<20$ years, pregnancy interval $<24$ months, increased parity, multiple gestations, $\mathrm{BMI}<18.5 \mathrm{~kg} / \mathrm{m}^{2}$, poor iron \& vitamin supplementation during pregnancy, low maternal haemoglobin level, maternal infections (syphilis, positive HIV status, and malaria), gestational age $<37$ weeks, and the number of antenatal care visits made during pregnancy have been identified as risk factors for low birth weight, premature birth, and stillbirth in low-income settings(23-28)(29)(30).

Although some studies have been conducted on the predictors of adverse pregnancy outcomes such as preterm birth, small-for-gestational-age, low birth weight and stillbirth in several sub-Saharan countries including some parts of Ghana, no study has reported the effect of ANC attendance on these adverse pregnancy outcomes in the North East region of Ghana. This study, therefore, aimed to determine the prevalence of adverse pregnancy outcomes and the association between ANC visits and preterm birth, small-for-gestational-age, stillbirth, and low birth weight among women in the North East Region of Ghana.

\section{Methods}

Data for the study were extracted from the birth records of mothers delivered at the Baptist Medical Centre between January 2018 to December 2018. All deliveries in the maternity unit of the hospital, including the antenatal activities of women, are captured in a birth register by Registered Nurses and Midwives. Upon approval from the hospital management, two registered nurses were recruited and trained to extract and record information on maternal and infant characteristics from the birth register for 2018. A data extraction sheet was designed for the data extraction using Microsoft Excel spreadsheet and pretested on the birth records of May 2019. For the period January 2018 to December 2018, we extracted information on 3011 women delivered at the facility, from the register. However, data on 2907 deliveries were analysed after excluding data on abortions and entries with missing information on antenatal care attendance.

\section{Adverse pregnancy outcomes}

Preterm birth, small-for-gestational-age, low birth weight, and stillbirth are the adverse pregnancy outcomes of interest in this study. Based on the recommendation of the World Health Organisation(20,31), we classified live births before 37 completed weeks of gestation as preterm birth and birth weights less than $2.5 \mathrm{~kg}$ as low birth weight regardless of gestational age. The global reference for foetal-weight and birth weight percentiles(32) was used to determine small-for-gestational-age based on the birth weight and standard deviation at 40 weeks completed gestation for our study cohort. A baby born with no signs of life at or after 28 weeks' gestation was captured in the birth register as stillbirth and this was extracted for the analysis.

\section{Primary exposure}

The number of antenatal care visits attended during pregnancy is the primary exposure of interest in this analysis. This was obtained from the antenatal records of all woman who reported to the labour and 
maternity unit of the hospital for delivery as part of the routine healthcare services offered to expectant mothers.

\section{Potential confounders}

The potential confounders considered in this analysis were mothers age at birth, occupation, number of pregnancies ever experienced, gestational age (in weeks), type of delivery, and sex of infants. To avoid data sparsity due to small numbers in some ages, mothers age was categories into $<20,20-30$, and $>30$ years. Occupation was grouped into two categories, housewife and "other". The "other" category consisted of occupations such as farmer, trader, teacher, seamstress, a hairdresser that had very small numbers. Type of delivery was categorised into vaginal delivery and caesarean section.

\section{Data analysis}

Stata version 16 (Stata Corp, College Station, TX, USA) was used to conduct the analysis. The data were checked for errors, inconsistencies, and explored for the extent of missing data. An indicator variable was created for missing values and cross-tabulated with the outcome variables and other important covariates to assess for a pattern. We did not find any consistent pattern, and those for which data were missing were not different from those who had complete data. Background characteristics of mothers were summarised by the number of antenatal care visits they attended during pregnancy using the chisquared test. The prevalence of each adverse pregnancy outcome was estimated, and the outcomes summarised by the number of antenatal care visits. We assessed for trend across three categories $(0,1-4$, and $>4$ ) of antenatal visits using the nonparametric test for a trend by Cuzick(33) (which is an extension of the Wilcoxon rank-sum test) with the "nptrend" command in Stata.

The association between antenatal care attendance and the adverse pregnancy outcomes was assessed using binary logistic regression. The crude odds ratios, $95 \%$ confidence intervals and likelihood ratio $p$ values for the effect of antenatal care on each of the outcomes was initially determined. In the multivariable analysis, the potential confounders were introduced one at a time into the model starting with confounders with the strongest confounding effect. These factors were retained in the final multivariable model if they caused an important change in the odds ratio for the association between antenatal visits and each of the outcomes. Adjusted odds ratios, $95 \%$ confidence intervals, and likelihood ratio $p$-values were used to summarise the adjusted effect of antenatal visits on each of the outcomes. To assess whether the effect of antenatal visits on preterm birth and low birth weight was modified by mothers age, we modelled an interaction between antenatal visits and mothers age using the likelihood ratio test.

\section{Results}

\section{Characteristics of the Study Sample}


Overall, 2907 women were included in the study. Most of them were aged $20-30$ years (59.2\%), delivered through the vagina $(79.8 \%)$ and were housewives $(70.8 \%$ ) (Table 1$)$. For $30.6 \%$ of the women, the current pregnancy was their first and more than half $(55.2 \%)$ of them delivered after 40 weeks of gestation. A little over half of all the children delivered were males (51.4\%).

Overall, a higher proportion of those who attended 1-4 ANC visits (57.2\%) and those who attended more than four ANC visits (62.7\%) were aged 20-30 years (Table 1). Adolescent mothers attended the least number of $1-4(21.3 \%)$ and more than $4(12.2 \%)$ antenatal visits during the period. However, of the 149 mothers who never attended any ANC visits during pregnancy, only $20.1 \%$ of them were adolescents. A higher proportion of those who attended more than 4 ANC visits were housewives (66.8\%) and $55.5 \%$ of them delivered after 40 weeks gestation and $76.6 \%$ had a vaginal delivery.

Table 1 Characteristics of the Study Sample

\begin{tabular}{|c|c|c|c|c|c|}
\hline \multirow[t]{2}{*}{ Characteristics } & \multicolumn{3}{|c|}{ Antenatal visits } & \multirow{2}{*}{$\begin{array}{l}\text { All women in the } \\
\text { sample }(n=2907)\end{array}$} & \multirow{2}{*}{$\begin{array}{l}\text { Chi-squared } \\
\text { P-value }\end{array}$} \\
\hline & $\begin{array}{c}\text { None } \\
(n=149)\end{array}$ & $\begin{array}{c}1-4 \\
(n=1547)\end{array}$ & $\begin{array}{c}>4 \\
(\mathrm{n}=1211)\end{array}$ & & \\
\hline \multicolumn{6}{|l|}{$\begin{array}{l}\text { Mothers age (in } \\
\text { years) }\end{array}$} \\
\hline$<20$ & $30(20.1)$ & $329(21.3)$ & $148(12.2)$ & $507(17.5)$ & $<0.001$ \\
\hline $20-30$ & $76(51.0)$ & $883(57.2)$ & $759(62.7)$ & $1719(59.2)$ & \\
\hline$>30$ & $43(28.9)$ & $332(21.5)$ & $303(25.1)$ & $678(23.3)$ & \\
\hline \multicolumn{6}{|l|}{ Occupation } \\
\hline Other & $46(30.9)$ & $394(25.7)$ & $405(33.6)$ & $845(29.2)$ & $<0.001$ \\
\hline House wife & $103(69.1)$ & $1141(74.3)$ & $800(66.4)$ & $2045(70.8)$ & \\
\hline \multicolumn{6}{|l|}{$\begin{array}{l}\text { Number of } \\
\text { pregnancies }\end{array}$} \\
\hline 1 & $45(30.2)$ & $507(32.8)$ & $337(27.8)$ & $889(30.6)$ & 0.003 \\
\hline 2 & $23(15.4)$ & $255(16.5)$ & $257(21.2)$ & $536(18.4)$ & \\
\hline 3 & 19(12.8) & 234(15.1) & $202(16.7)$ & 455(15.7) & \\
\hline 4 & $21(12.1)$ & $187(12.1)$ & $170(14.0)$ & 378(13.0) & \\
\hline 5 & $13(8.7)$ & $159(10.3)$ & $111(9.2)$ & 283(9.7) & \\
\hline $6+$ & $28(18.8)$ & $204(13.2)$ & 134(11.1) & $366(12.6)$ & \\
\hline \multicolumn{6}{|l|}{$\begin{array}{l}\text { Gestational age } \\
\text { in weeks }\end{array}$} \\
\hline$<31$ weeks & $6(4.1)$ & 28(1.9) & $6(0.5)$ & $40(1.4)$ & $<0.001$ \\
\hline 31-36 weeks & $25(16.9)$ & $176(11.7)$ & $110(9.4)$ & $311(11.0)$ & \\
\hline $37-40$ weeks & $26(17.5)$ & $484(32.1)$ & $407(34.6)$ & $917(32.4)$ & \\
\hline$>40$ weeks & $91(61.5)$ & $818(54.3)$ & $652(55.5)$ & $1562(55.2)$ & \\
\hline \multicolumn{6}{|l|}{ Sex of child } \\
\hline Female & $67(45.9)$ & $742(48.2)$ & $598(49.5)$ & $1408(48.6)$ & 0.633 \\
\hline Male & $79(54.1)$ & 799(51.8) & $611(50.5)$ & $1489(51.4)$ & \\
\hline \multicolumn{6}{|l|}{ Type of delivery } \\
\hline Vaginal Delivery & $100(69.9)$ & $1252(83.2)$ & $906(76.6)$ & 2259(79.8) & $<0.001$ \\
\hline $\begin{array}{l}\text { Caesarean } \\
\text { section }\end{array}$ & $43(30.1)$ & $253(16.8)$ & $277(23.4)$ & $573(20.2)$ & \\
\hline
\end{tabular}


Of the four adverse pregnancy outcomes assessed in this study, preterm birth had the highest prevalence of $12.4 \%$ (Table 2). Low birth weight was prevalent in $9.3 \%$ of the children born during the period. Of the 2907 mothers, $4.8 \%$ delivered babies that were small for their gestational age and $2 \%$ had a stillbirth.

We found evidence for an inverse trend in the chi-squared association between ANC visits and the prevalence of adverse pregnancy outcomes (Table 2). An increase in the number of ANC visits was associated with a decrease in the number of adverse pregnancy outcomes. For instance, about $21 \%$ of mothers who never attended any ANC visits, $13.6 \%$ of those who attended $1-4$ visits and $10 \%$ of those who attended more than four visits had a preterm birth, respectively $\left(P_{\text {trend }}<0.001\right.$, Table 2$)$. Likewise, small-for-gestational-age was prevalent in $6.8 \%$ of mothers who never attended any ANC visits, $5.6 \%$ in those who made $1-4$ visits, and $3.4 \%$ in those who made more than four visits. As shown in Table 2, similar trends were observed for low birth weight $\left(P_{\text {trend }}<0.001\right)$ and stillbirth $\left(P_{\text {trend }}<0.003\right)$.

Figure 1 presents the four adverse pregnancy outcomes by mothers' age. It shows that adolescent mothers had the highest prevalence of preterm birth (12.9\%), low birth weight (12.1), and small-forgestational-age (6.4\%). For stillbirth, the highest proportion was observed among mothers aged 2030 years $(2.2 \%)$.

Table 2 Prevalence of adverse pregnancy outcomes

\begin{tabular}{|c|c|c|c|c|c|}
\hline \multirow{2}{*}{$\begin{array}{l}\text { Adverse birth } \\
\text { outcomes }\end{array}$} & \multicolumn{3}{|c|}{ Antenatal visits } & \multirow{2}{*}{$\begin{array}{l}\text { All women in the } \\
\text { sample }(n=2907)\end{array}$} & \multirow{2}{*}{$\begin{array}{l}\text { Chi-squared P- } \\
\text { value for trend }\end{array}$} \\
\hline & $\begin{array}{c}\text { None } \\
(n=149)\end{array}$ & $\begin{array}{c}1-4 \\
(n=1547)\end{array}$ & $\begin{array}{c}>4 \\
(n=1211)\end{array}$ & & \\
\hline \multicolumn{6}{|l|}{ Preterm birth } \\
\hline No & 117(79.1) & $1302(86.6)$ & $1059(90.1)$ & $2479(87.6)$ & $<0.001$ \\
\hline Yes & $31(20.9)$ & 204(13.6) & $116(9.9)$ & $351(12.4)$ & \\
\hline \multicolumn{6}{|l|}{$\begin{array}{l}\text { Low birth } \\
\text { weight }\end{array}$} \\
\hline No & $128(87.7)$ & $1360(88.3)$ & $1137(94.0)$ & $2626(90.7)$ & $<0.001$ \\
\hline Yes & 18(12.3) & 180(11.7) & $72(6.0)$ & $270(9.3)$ & \\
\hline \multicolumn{6}{|c|}{$\begin{array}{l}\text { Small-for- } \\
\text { gestational-age }\end{array}$} \\
\hline No & 138(93.2) & $1421(94.4)$ & 1135(96.6) & 2694(95.2) & 0.004 \\
\hline Yes & $10(6.8)$ & $85(5.6)$ & $40(3.4)$ & $135(4.8)$ & \\
\hline \multicolumn{6}{|l|}{ Stillbirth } \\
\hline No & 138(92.6) & $1520(98.3)$ & $1192(98.4)$ & $2851(98.0)$ & 0.003 \\
\hline Yes & $11(7.4)$ & 27(1.8) & 19(1.6) & $57(2.0)$ & \\
\hline
\end{tabular}

\section{Association of number of antenatal care visits and adverse pregnancy outcomes}

There was evidence for an association between ANC visits and preterm birth in the unadjusted analysis $(p<0.001)$. After adjusting for mothers age, the number of pregnancies, type of delivery, sex of a child, and mothers' occupation the strength of the evidence reduced $(p=0.041)$. Overall, mothers who attended any number of ANC visits had lower odds of preterm birth compared to those who did not attend any ANC visit (Table 3). However, the protective effect of ANC visits on preterm birth varied with the number of 
visits attended. For instance, compared to mothers who did not attend any ANC visit, those who attended only 1 visit were $10 \%$ less likely to have preterm birth (OR $0.90,95 \% \mathrm{Cl} 0.48-1.68)$, those who attend 2 ANC visits were $13 \%$ less likely to have preterm birth (OR $0.87,95 \% \mathrm{Cl} 0.52-1.44)$, while those who attended 5 and 6 ANC visits were $55 \%(\mathrm{OR} 0.45,95 \% \mathrm{Cl} 0.27-0.75)$ and $62 \%(\mathrm{OR} 0.38,95 \% \mathrm{Cl} 0.22-0.65)$ less likely to have preterm birth in the adjusted analysis, respectively.

To determine whether the association between ANC visits and preterm birth differed by mothers age, we assessed for interaction between ANC visits and mothers age (Table 5). There was good evidence that the data were consistent with an interaction between ANC visits and mothers age $(p=0.035)$. Among mothers who did not attend any ANC visits, the odds of preterm birth were $53 \%$ and $45 \%$ less likely in adolescent mothers (OR 0.47, 95\% $\mathrm{Cl} 0.14-1.56$ ) and older mothers (OR 0.55, 95\% $\mathrm{Cl} 0.20-1.56$ ) compared to those aged 20-30years, respectively. Among mothers who attended more than four ANC visits, the odds of preterm birth were nearly 2 times and 1.2 times more likely in adolescent mothers (OR 1.78, $95 \% \mathrm{Cl} 1.03-3.05)$ and older mothers (OR $1.16,95 \% \mathrm{Cl} 0.71-1.92)$ compared to those aged 20-30years.

In both the unadjusted $(p<0.001)$ and adjusted $(p<0.001)$ analysis, ANC visits were associated with low birth weight. After adjusting for mothers age, gestational age, the number of pregnancies, type of delivery, sex of a child, and mothers' occupation there was an increase in all the odds ratios, except for the odds ratio for seven or more visits (Table 4). Gestational age, number of pregnancies, and mother's occupation caused a substantial change in the odds ratios when they were introduced into the model; however, mothers age did not produce a considerable change. Furthermore, in the adjusted analysis, there was evidence for a linear trend in the effect of ANC visits on low birth weight $\left(P_{\text {trend }}<0.001\right)$. An increase in the number of ANC visits was associated with decreased odds of low birth weight. For example, those who attended only 1 ANC visit had double the odds of low birth weight (OR 1.82,95\% Cl 0.87-3.78), 2 and 3 visits were associated with $1.4(95 \% \mathrm{Cl} 0.72-2.61)$ and $1.1(95 \% \mathrm{Cl} 0.56-1.97)$ times higher odds of low birth weight, whiles 4 and 5 visits were associated with $22 \%(\mathrm{OR} 0.78,95 \% \mathrm{Cl} 0.42-1.46)$ and $43 \%(\mathrm{OR}$ $0.57,95 \% \mathrm{Cl} 0.29-1.10$ ) decreased odds of low birth weight compared to mothers who never attended any ANC visits.

Further analysis revealed that there was strong evidence for an interaction between ANC visits and mothers age $(p<0.001)$, indicating that the effect of ANC visits on low birth weight differed depending on the age of the mother (Table 5). Among mothers who never attended any ANC visits, the odds of low birth weight were 1.3 times and 4.5 times more likely in adolescent mothers (OR $1.34,95 \% \mathrm{Cl} 0.29-6.23$ ) and mothers older than 30 years (OR 4.49,95\% $\mathrm{Cl} 1.31-15.34$ ) compared to those aged 20-30years, respectively. However, among mothers who attended more than four ANC visits, the odds of low birth weight were 1.2 times more likely in adolescent mothers (OR $1.20,95 \% \mathrm{Cl} 0.61-2.34$ ) and $43 \%$ less likely in mothers older than 30years (OR $0.57,95 \% \mathrm{Cl} 0.26-1.27$ ) compared to those aged 20-30years.

There was good evidence for an association between ANC visits and small-for-gestational-age in the unadjusted $(P=0.016)$ and adjusted analysis $(P=0.021)$. When we adjusted for mothers age, the number of pregnancies, type of delivery, sex of a child, and mothers' occupation, the odds of small-for-gestational- 
age was 1.6 times more likely and $2 \%$ less likely in mothers who attended only one ANC visit $(95 \% \mathrm{Cl} 0.66$ 3.97) and those who attended two ANC visits (OR 0.98, 95\% $\mathrm{Cl} 0.43-2.23)$ compared to those who did not attend any ANC visits, respectively (Table 4). While mothers who attended six ANC visits (OR $0.48,95 \% \mathrm{Cl}$ $0.20-1.17$ ) and those who attended seven or more visits (OR $0.46,95 \% \mathrm{Cl} 0.18-1.15$ ) were $52 \%$ and $54 \%$ less likely to have delivered small-for-gestational-age babies compared to those who did not attend any ANC visit in the adjusted analysis, respectively (Table 4).

We found evidence for an association between ANC visits and stillbirth in the unadjusted $(P<0.001)$ and adjusted analysis $(P<0.001)$. Overall, the adjusted analysis showed that mothers who attended any number of ANC visits were less likely to experience stillbirth compared to those who did not attend any ANC visit (Table 4). For instance, mothers who attended only 1 ANC visit (OR $0.62,95 \% \mathrm{Cl} 0.19-2.07$ ) and those who attended seven or more visits (OR $0.25,95 \% \mathrm{Cl} 0.07-0.86$ ) were $38 \%$ and $75 \%$ less likely to have experienced stillbirth compared to those who never attended any ANC visits, respectively.

Table 3 Unadjusted odds ratios and 95\% confidence intervals of the association between antenatal care attendance and adverse pregnancy outcomes

\begin{tabular}{|c|c|c|c|c|}
\hline Antenatal visits & $\begin{array}{l}\text { Preterm } \\
\text { birth }\end{array}$ & $\begin{array}{l}\text { Low birth } \\
\text { weight }\end{array}$ & $\begin{array}{c}\text { Small-for-gestational } \\
\text { age }\end{array}$ & Stillbirth \\
\hline $\begin{array}{l}\text { Number of antenatal } \\
\text { visits }\end{array}$ & $\mathrm{P}<0.001$ & $\mathrm{P}<0.001$ & $\mathrm{P}=0.016$ & $\mathrm{p}<0.001$ \\
\hline 0 & 1 & 1 & 1 & 1 \\
\hline 1 & $\begin{array}{l}0.81(0.44- \\
1.50)\end{array}$ & $\begin{array}{l}1.78(0.91- \\
3.46)\end{array}$ & $1.69(0.71-4.01)$ & $\begin{array}{l}0.55(0.18- \\
1.62)\end{array}$ \\
\hline 2 & $\begin{array}{l}0.83(0.51- \\
1.35)\end{array}$ & $\begin{array}{l}1.27(0.71- \\
2.27)\end{array}$ & $1.00(0.46-2.17)$ & $\begin{array}{l}0.44(0.19- \\
1.04)\end{array}$ \\
\hline 3 & $\begin{array}{l}0.47(0.29- \\
0.77)\end{array}$ & $\begin{array}{l}0.92(0.52- \\
1.62)\end{array}$ & $0.80(0.37-1.70)$ & $\begin{array}{l}0.14(0.05- \\
0.40)\end{array}$ \\
\hline 4 & $\begin{array}{l}0.53(0.33- \\
0.84)\end{array}$ & $\begin{array}{l}0.66(0.38- \\
1.17)\end{array}$ & $0.61(0.29-1.29)$ & $\begin{array}{c}0.12(0.04- \\
0.33)\end{array}$ \\
\hline 5 & $\begin{array}{l}0.45(0.27- \\
0.73)\end{array}$ & $\begin{array}{l}0.53(0.29- \\
0.96)\end{array}$ & $0.48(0.22-1.08)$ & $\begin{array}{l}0.30(0.13- \\
0.69)\end{array}$ \\
\hline 6 & $\begin{array}{l}0.35(0.20- \\
0.59)\end{array}$ & $\begin{array}{l}0.35(0.18- \\
0.70)\end{array}$ & $0.46(0.20-1.10)$ & $\begin{array}{l}0.10(0.03- \\
0.36)\end{array}$ \\
\hline $7+$ & $\begin{array}{c}0.45(0.26- \\
0.76)\end{array}$ & $\begin{array}{c}0.44(0.22- \\
0.88)\end{array}$ & $0.52(0.22-1.25)$ & $\begin{array}{l}0.17(0.05- \\
0.53)\end{array}$ \\
\hline
\end{tabular}

Table 4 Adjusted odds ratios and 95\% confidence intervals of the association between antenatal care attendance and adverse pregnancy outcomes 


\begin{tabular}{|c|c|c|c|c|}
\hline Antenatal visits & $\begin{array}{l}\text { Preterm } \\
\text { birth }^{\mathrm{a}}\end{array}$ & $\begin{array}{l}\text { Low birth } \\
\text { weight }\end{array}$ & $\begin{array}{c}\text { Small-for-gestational } \\
\text { age }^{c}\end{array}$ & Stillbirth $^{\mathrm{d}}$ \\
\hline $\begin{array}{l}\text { Number of antenatal } \\
\text { visits }\end{array}$ & $\mathrm{P}=0.041$ & $\mathrm{P}<0.001$ & $P=0.021$ & $\mathrm{P}<0.001$ \\
\hline 0 & 1 & 1 & 1 & 1 \\
\hline 1 & $\begin{array}{l}0.90(0.48- \\
1.68)\end{array}$ & $\begin{array}{l}1.82(0.87- \\
3.78)\end{array}$ & $1.62(0.66-3.97)$ & $\begin{array}{l}0.62(0.19- \\
2.07)\end{array}$ \\
\hline 2 & $\begin{array}{l}0.87(0.52- \\
1.44)\end{array}$ & $\begin{array}{l}1.37(0.72- \\
2.61)\end{array}$ & $0.98(0.43-2.23)$ & $\begin{array}{l}0.44(0.16- \\
1.22)\end{array}$ \\
\hline 3 & $\begin{array}{l}0.50(0.30- \\
0.83)\end{array}$ & $\begin{array}{c}1.05(0.56- \\
1.97)\end{array}$ & $0.81(0.37-1.80)$ & $\begin{array}{l}0.18(0.06- \\
057)\end{array}$ \\
\hline 4 & $\begin{array}{l}0.56(0.35- \\
0.91)\end{array}$ & $\begin{array}{l}0.78(0.42- \\
1.46)\end{array}$ & $0.65(0.29-1.42)$ & $\begin{array}{l}0.18(0.06- \\
0.53)\end{array}$ \\
\hline 5 & $\begin{array}{l}0.45(0.27- \\
0.75)\end{array}$ & $\begin{array}{l}0.57(0.29- \\
1.10)\end{array}$ & $0.45(0.19-1.06)$ & $\begin{array}{l}0.41(0.16- \\
1.04)\end{array}$ \\
\hline 6 & $\begin{array}{l}0.38(0.22- \\
0.65)\end{array}$ & $\begin{array}{l}0.46(0.22- \\
0.95)\end{array}$ & $0.48(0.20-1.17)$ & $\begin{array}{l}0.16(0.04- \\
0.61)\end{array}$ \\
\hline $7+$ & $\begin{array}{l}0.47(0.27- \\
0.81)\end{array}$ & $\begin{array}{l}0.44(0.21- \\
0.93)\end{array}$ & $0.46(0.18-1.15)$ & $\begin{array}{l}0.25(0.07- \\
0.86)\end{array}$ \\
\hline
\end{tabular}

a adjusted for mothers age, number of pregnancies, type of delivery, sex of child, and mothers occupation

$\mathrm{b}$ adjusted for mothers age, gestational age, the number of pregnancies, type of delivery, sex of a child, and mothers' occupation.

$\mathrm{C}$ adjusted for mothers age, the number of pregnancies, type of delivery, sex of a child, and mothers occupation.

$\mathrm{d}$ adjusted for mothers age, gestational age, the number of pregnancies, type of delivery, sex of a child, and mothers' occupation.

Table 5 Adjusted odds ratios and 95\% confidence intervals of the interaction between antenatal care attendance mothers age on adverse pregnancy outcomes

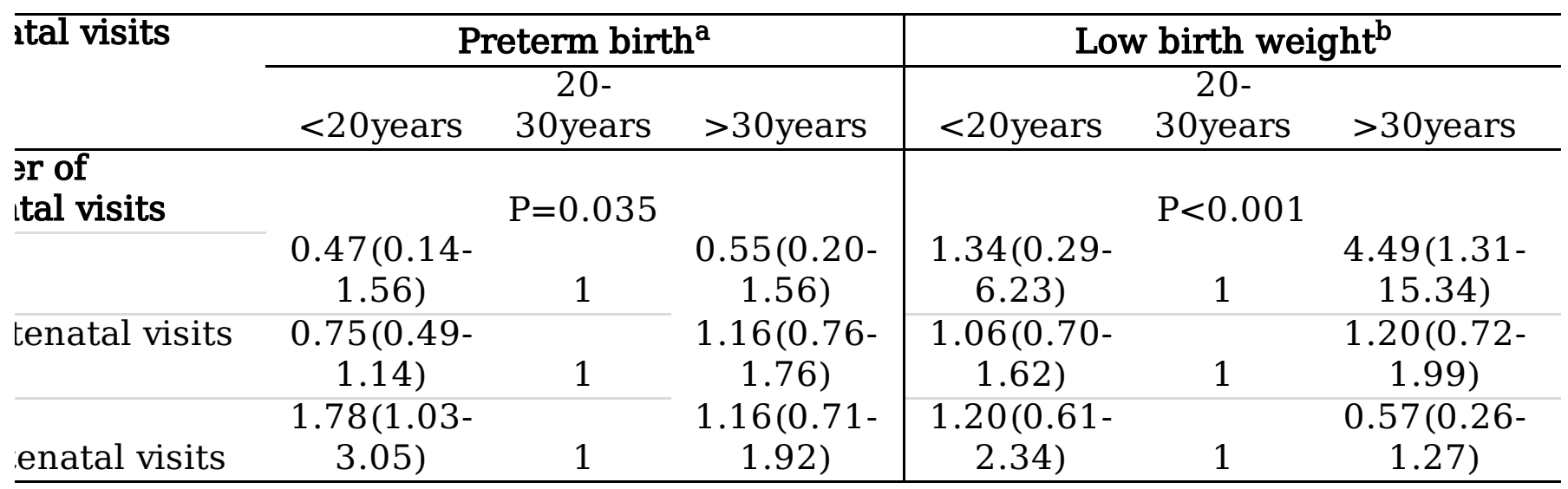

a adjusted for mothers age, number of pregnancies, type of delivery, sex of child, and mothers occupation

$\mathrm{b}$ adjusted for mothers age, gestational age, the number of pregnancies, type of delivery, sex of a child, and mothers' occupation. 


\section{Discussion}

We found that there was an association between ANC attendance and adverse pregnancy outcomes. Our analysis showed that ANC attendance offered some protection against preterm birth, low birth weight, small-for-gestational-age, and stillbirth in the study sample, albeit with variations in the protective effect depending on the number of visits attended. An increased in the number of ANC visits was associated with a decrease in the occurrence of the adverse pregnancy outcomes, except for low birth weight where the protective effect was observed only after four ANC visits. Our findings are in accord with previously reported associations in Ghana and other low- and middle-income settings(3,34-38). These findings highlight the importance of ANC during pregnancy and the need for every pregnant woman to initiate and ensure adequate ANC contacts. A detailed, comprehensive guideline on routine ANC for pregnant women by the $\mathrm{WHO}$ is presented elsewhere (39).

There are several possible pathways to explain the observed protective effect of ANC attendance on the adverse pregnancy outcomes assessed in this study. First, antenatal care provides an opportunity for the early detection and appropriate management of pregnancy-related complications such as anaemia, malaria, gestational diabetes, infections, hypertension which are known to cause preterm birth, stillbirth, low birth weight, and small-for-gestational-age(40-42). Through antenatal assessment, women with these risk factors are identified and advised on the signs of complications, birth preparedness, and offered distinct attention to prevent adverse outcomes. For instance, as part of the services rendered during antenatal care pregnant women are vaccinated against tetanus, screened, and treated for infections such syphilis, gonorrhoea; and receive folic acid, vitamin B12, and iron to prevent anaemia. Also, midwives and nurses provide education on appropriate nutrition during pregnancy and distribute treated bed nets during ANC visits to prevent malaria. Further, pregnant women are examined for high blood pressure and proteinuria as part of the care rendered during antenatal visits and this ensures early diagnosis and management of hypertension in pregnancy.

Adolescent mothers attended the least number of ANC visits during the study period. Our analysis suggests that the effect of ANC attendance on preterm birth and low birth weight differed depending on the age of the mother, which is consistent with a previous study in Brazil(43). Among mothers who never attended any ANC visits, adolescent mothers and older mothers had higher odds of low birth weight compared to mothers aged 20-30years. In line with our results, a comparative study in Ethiopia found that advanced maternal age was associated with 3-fold increased risk of preterm birth(44). Surprisingly, the odds of preterm birth among the mothers who never attended any ANC visits was lower in adolescent mothers and older mothers compared to mothers aged 20-30years. This finding is inconsistent with a comparative study in Ethiopia which reported a 4-fold increased risk of preterm birth among older women(44). The Ethiopian study had a relatively smaller sample and unlike our study, it was conducted in a tertiary level facility and the characteristics of the participant may differ from those included in this study, which may explain the inconsistency in the findings. Nonetheless, it will be useful for future studies to explore this interaction further with a larger and more representative sample. 
For mothers who attended four or more ANC visits, the odds of low birth weight were higher in adolescent mothers and lower in older mothers compared to mothers aged 20-30years. However, the odds of preterm birth among the mothers who attended more than four ANC visits was higher in adolescent mothers and older mothers compared to mothers aged 20-30years. These findings support a recent study in Brazil that reported the highest rate of adverse pregnancy outcome among adolescents with inadequate prenatal care(43). The results highlight the need to prioritise adolescents and older pregnant women for antenatal care.

The major strength of this study is the large sample analysed, and as a result, our estimates may have a higher degree of precision than earlier studies that examined similar associations in Ghana. It also strengthens the generalizability of our findings. Also, our findings showed a dose-response effect between the number of ANC visits and adverse pregnancy outcomes, which earlier studies in Ghana did not assess. Though we conducted the study at a single centre, it captured many residents on a broader boundary since the study setting is a major referral centre serving several communities across northern Ghana. Despite the strengths, there are some limitations that should be considered when interpreting the findings of this study. A variety of maternal sociodemographic and obstetric characteristics such as education, income, rural-urban residence was not controlled in these analyses because the secondary data source lacked information on many potential confounders. As a result, there is a possibility that residual confounding may have distorted the accuracy of the estimates. Also, the analysis used crosssectional data and a causal relationship cannot be drawn from the observed associations. A nationally representative prospective study could provide further evidence of the observed associations.

\section{Abbreviations}

ANC: Antenatal Care

IPTO-SP: Intermittent Preventive Treatment in pregnancy with sulfadoxine-pyrimethamine

LBW: Low Birth Weight

PTB: preterm Birth

SB: Stillbirth

SGA: Small-for-gestational-age

WHO: World Health Organisation

\section{Declarations}

\section{Ethics approval and consent to participate}


The relevant authorities of the Baptist Medical Centre in the North East Region of Ghana granted approval and permission for the authors to use the healthcare records of the maternity unit of the hospital for this study. We did not capture identifying information from the records and the confidentiality of the information extracted from the records was ensured in accordance with the data protection act.

\section{Consent for publication}

Not applicable

\section{Availability of data and material}

The datasets used and/or analysed during the current study are available from the corresponding author on reasonable request.

\section{Competing interests}

The authors declare that they have no competing interests.

\section{Funding}

No funding was received for this study.

\section{Authors' contributions}

SM and ASA conceived and designed the study, wrote the protocol, and performed the statistical analysis. IY, WJS and YHY managed the literature search and the discussion of the findings. SM, and ASA designed the data capture sheet and retrieved the data from the facility records. SM, IY, and ASA drafted the manuscript. YHY and WJS reviewed the manuscript. All authors read and approved the final manuscript.

\section{Acknowledgements}

The authors would like to thank the management and staff of the Baptist Medical Centre for their cooperation during the study.

\section{References}

1. Bierhoff M, Angkurawaranon C, Myat Min A, Gilder ME, Win Tun N, Keereevijitt A, et al. Maternal Hepatitis B Infection Burden, Comorbidity and Pregnancy Outcome in a Low-Income Population on the Myanmar-Thailand Border: A Retrospective Cohort Study. J Pregnancy. 2019;2019.

2. Chaibva BV, Olorunju S, Nyadundu S, Beke A. Adverse pregnancy outcomes, "stillbirths and early neonatal deaths" in Mutare district, Zimbabwe (2014): A descriptive study. BMC Pregnancy Childbirth. 2019;19(1):1-7. 
3. Awoleke JO, Olofinbiyi BA. Poor prenatal service utilization and pregnancy outcome in a tertiary health facility in southwest Nigeria. Pan Afr Med J. 2020;35:1-10.

4. Yideg Yitbarek G, Ayele BA. Prevalence of Syphilis among Pregnant Women Attending Antenatal Care Clinic, Sede Muja District, South Gondar, Northwest Ethiopia. J Pregnancy. 2019;2019:1584527.

5. Yeoh PL, Hornetz K, Dahlui M. Antenatal care utilisation and content between low-risk and high-risk pregnant women. PLoS One. 2016;11(3):1-17.

6. WHO. WHO recommendations on antenatal care for a positive pregnancy experience. Geneva, Switzerland; 2016.

7. World Health Organization. WHO facts sheet:Maternal mortality. world health organisation, Geneva. 2020.

8. World Health Organization. Newborns: improving survival and well-being. World health organisation, Geneva. 2020.

9. Dassah ET, Adu-Sarkodie Y, Mayaud P. Factors associated with failure to screen for syphilis during antenatal care in Ghana: A case control study. BMC Infect Dis. 2015;15(1):1-9.

10. Hawkes SJ, Gomez GB, Broutet N. Early Antenatal Care: Does It Make a Difference to Outcomes of Pregnancy Associated with Syphilis? A Systematic Review and Meta-Analysis. PLoS One. 2013;8(2).

11. Turyakira E, White LJ, Nabasumba C, Tumwebaze B, Muehlenbachs A, Guerin PJ, et al. Impact of malaria during pregnancy on pregnancy outcomes in a Ugandan prospective cohort with intensive malaria screening and prompt treatment. Malar J. 2013;12:139.

12. Amoakoh-Coleman M, Borgstein ABJ, Sondaal SFV, Grobbee DE, Miltenburg AS, Verwijs M, et al. Effectiveness of mHealth interventions targeting health care workers to improve pregnancy outcomes in low- and middle-income countries: A systematic review. J Med Internet Res. 2016;18(8):1-18.

13. Tafere TE, Afework MF, Yalew AW. Providers adherence to essential contents of antenatal care services increases birth weight in Bahir Dar City Administration, north West Ethiopia: A prospective follow up study 11 Medical and Health Sciences 1117 Public Health and Health Services 11 Medic. Reprod Health. 2018;15(1):1-8.

14. Asundep NN, Carson AP, Turpin CA, Tameru B, Agidi AT, Zhang K, et al. Determinants of access to antenatal care and birth outcomes in Kumasi, Ghana. J Epidemiol Glob Health. 2013;3(4):279-88.

15. UNICEF and WHO. Antenatal care. UNICEF Data: Monitoring the situation of children and women. 2020 .

16. Mbuagbaw L, Habiba Garga K, Ongolo-Zogo P. Health system and community level interventions for improving antenatal care coverage and health outcomes. Cochrane Database Syst Rev. 2014;2014(2).

17. Asundep NN, Jolly PE, Carson A, Turpin CA, Zhang K, Tameru B. Antenatal Care Attendance , a Surrogate for Pregnancy Outcome? The Case of Kumasi , Ghana. 2014;1085-94. 
18. World Health Organization. Born Too Soon: The Global Action Report on Preterm Birth. Geneva, Switzerland; 2012.

19. Kinney M V, Lawn JE, Howson CP, Belizan J. 15 million preterm births annually: what has changed this year? Reprod Health. 2012;9(28):2-5.

20. World Health Organization. WHO recommendations on interventions to improve preterm birth outcomes. Geneva, Switzerland: World Health Organization; 2015. 1-108 p.

21. Blencowe H, Krasevec J, Onis M De, Black RE, An X, Stevens GA, et al. National, regional , and worldwide estimates of low birthweight in 2015 , with trends from 2000: a systematic analysis. Lancet Glob Heal. 2015;7:e849-60.

22. Lawn JE, Blencowe H, Pattinson R, Cousens S, Kumar R, lbiebele I, et al. Stillbirths 2 Stillbirths: Where? When? Why? How to make the data count? Lancet. 2011;377(9775):1448-63.

23. Demelash H, Motbainor A, Nigatu D, Gashaw K, Melese A. Risk factors for low birth weight in Bale zone hospitals , South-East Ethiopia: a case - control study. BMC Pregnancy Childbirth. 2015;15(264):1-10.

24. AZIMUL S, MATIN A, SHABNAM J, SHAMIANAZ S, BANEERJE M. MATERNAL FACTORS AFFECTING LOW BIRTH WEIGHT IN URBAN AREA OF BANGLADESH. J Dhaka Med Coll. 2009;18(1):64-9.

25. Muchemi OM, Echoka E, Makokha A. Factors associated with low birth weight among neonates born at Olkalou District Hospital, Central Region, Kenya. Pan Afr Med J. 2015;20(108):1-11.

26. Mohammed S, Bonsing I, Yakubu I, Wondong WP. Maternal obstetric and socio-demographic determinants of low birth weight: A retrospective cross-sectional study in Ghana. Reprod Health. 2019;16(1):1-8.

27. Fonseca CRB da, Strufaldi2 MWL, Carvalho LR de, Puccini RF. Adequacy of antenatal care and its relationship with low birth weight in Botucatu, São Paulo, Brazil: a case-control study. BMC Pregnancy Childbirth. 2014;14(225).

28. Endalamaw A, Engeda EH, Ekubagewargies DT, Belay GM, Tefera MA. Low birth weight and its associated factors in Ethiopia: a systematic review and meta- analysis. Ital J Pediatr. 2018;44(141):1-12.

29. Abaraya M, Seid SS, Ibro SA. Determinants of preterm birth at Jimma University Medical Center, southwest Ethiopia. Pediatr Heal Med Ther. 2018;9:101-7.

30. Aminu M, Unkels R, Mdegela M, Utz B, Adaji S, Broek N van den. Causes of and factors associated with stillbirth in low- and middle-income countries: a systematic literature review. BJOG. 2014;121(suppl. 4):141-53.

31. UNICEF and WHO. Low Birthweight: Country, Regional and Global Estimates Contents. NewYork, USA; 2004.

32. Mikolajczyk RT, Zhang J, Betran AP, Souza JP, Mori R, Gülmezoglu AM, et al. A global reference for fetal-weight and birthweight percentiles. Lancet. 2011;377:1855-61. 
33. Armitage P. Tests for Linear Trends in Proportions and Frequencies Author ( $s$ ): P. Armitage. Biometrics. 1955;11(3):375-86.

34. Heaman MI, Newburn-Cook C V., Green CG, Elliott LJ, Helewa ME. Inadequate prenatal care and its association with adverse pregnancy outcomes: A comparison of indices. BMC Pregnancy Childbirth. 2008;8:1-8.

35. Ntui AN, Jolly PE, Carson A, Turpin CA, Zhang K, Berhanu T, et al. Antenatal care attendance, a surrogate for pregnancy outcome? The case of Kumasi, Ghan. Matern Child Heal J. 2016;18(5):1085-94.

36. Kasu ES, Ayim A, Tampuori J, Atimpo S. Retrospective cohort study of antenatal care and pregnancy outcomes in Kadjebi district of Ghana. J Biol Agric Healthc [Internet]. 2015;5(6):59-69. Available from: http://www.iiste.org/Journals/index.php/JBAH/article/view/20973

37. Brown CA, Sohani SB, Khan K, Lilford R, Mukhwana W. Antenatal care and perinatal outcomes in Kwale district, Kenya. BMC Pregnancy Childbirth. 2008;8:1-11.

38. Nimi T, Fraga S, Costa D, Campos P, Barros H. Prenatal care and pregnancy outcomes: A crosssectional study in Luanda, Angola. Int J Gynecol Obstet [Internet]. 2016;135:S72-8. Available from: http://dx.doi.org/10.1016/j.ijgo.2016.08.013

39. World Health Organization. WHO Recommendations on Antenatal Care for a Positive Pregnancy Experience. WHO Guidelines Approved by the Guidelines Review Committee. WHO Recommendations on Antenatal Care for a Positive Pregnancy Experience. World Health Organization; 2016.

40. Berhe AK, llesanmi AO, Aimakhu CO, Mulugeta A. Effect of pregnancy induced hypertension on adverse perinatal outcomes in Tigray regional state, Ethiopia: A prospective cohort study. BMC Pregnancy Childbirth. 2019;20(1):1-11.

41. Yang YY, Fang YH, Wang X, Zhang Y, Liu XJ, Yin ZZ. A retrospective cohort study of risk factors and pregnancy outcomes in 14,014 Chinese pregnant women. Med (United States). 2018;97(33):1-8.

42. Schmidt CB, Voorhorst I, Van De Gaar VHW, Keukens A, Potter Van Loon BJ, Snoek FJ, et al. Diabetes distress is associated with adverse pregnancy outcomes in women with gestational diabetes: $A$ prospective cohort study. BMC Pregnancy Childbirth. 2019;19(1):1-9.

43. Vieira CL, Coeli CM, Pinheiro RS, Brandão ER, Camargo KR, Aguiar FP. Modifying Effect of Prenatal Care on the Association Between Young Maternal Age and Adverse Birth Outcomes. J Pediatr Adolesc Gynecol. 2012;25(3):185-9.

44. Mehari MA, Maeruf $H$, Robles $C C$, Woldemariam S, Adhena T, Mulugeta M, et al. Advanced maternal age pregnancy and its adverse obstetrical and perinatal outcomes in Ayder comprehensive specialized hospital, Northern Ethiopia, 2017: A comparative cross-sectional study. BMC Pregnancy Childbirth. 2020;20(1):1-10.

\section{Figures}




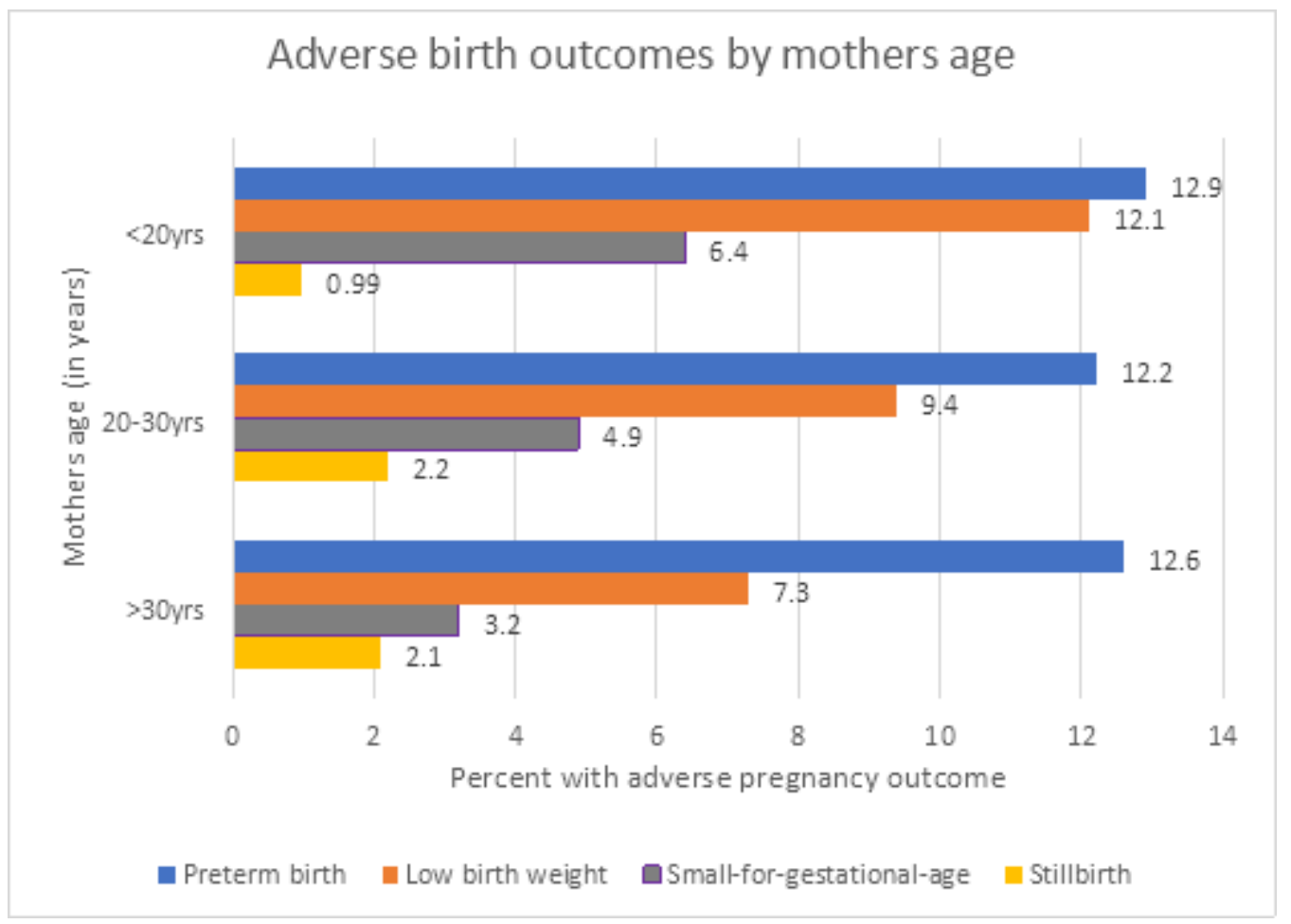

\section{Figure 1}

Prevalence of adverse pregnancy outcomes by mothers' age 